\title{
REPLACING ORTHOMETRIC HEIGHTS WITH ELLIPSOIDAL HEIGHTS IN ENGINEERING SURVEYS
}

\author{
0. T. Badejo ${ }^{1,}{ }^{*}$, K. F. A. Aleem ${ }^{2}$ and J. B. Olaleye ${ }^{3}$ \\ 1,3DEPARTMENT OF SURVEYING AND GEOINFORMATICS, UNIVERSITY OF LAGOS, LAGOS STATE, NIGERIA

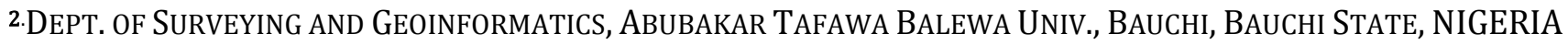 \\ E-mail addresses:1tbadejo@unilag.edu.ng, 2 akfaleem@yahoo.com,3 jb_ola@yahoo.com
}

\begin{abstract}
Differential Global Positioning System (DGPS) is one of the most frequently used positioning methods in geodesy. The end products of surveying with Global Navigation Satellite Systems (GNSS)are geodetic latitude ( $\phi$ ), geodetic longitude ( $\lambda$ ) and ellipsoidal height (h) which are obtained with reference to the ellipsoid. Recent developments in GNSS technology make us to obtain the ellipsoidal height with high accuracy. In engineering practice, orthometric heights (height above sea level) are always used. The orthometric heights are determined by spirit or geodetic leveling. In transforming the GNSS-derived ellipsoidal heights to orthometric heights, it is important to know the separation between the ellipsoidal and the geoid surface. This work investigates the use of ellipsoidal heights in place of orthometric heights for engineering surveys. DGPS observations were carried out to obtain the ellipsoidal heights for a number of points in the study area in Port Harcourt, Nigeria. Orthometric heights for the same set of points were determined using geodetic levelling. The results satisfied third order levelling which is good enough for engineering surveys.
\end{abstract}

Keywords: orthometric heights, ellipsoidal heights, global positioning system, engineering surveys, levelling

\section{INTRODUCTION}

There are three basic geodetic surfaces, these are the geoid, the earth (topographic surface) and the ellipsoid. The relationship between these surfaces is shown in Figure 1.Reference ellipsoid may be defined as a surface whose plane sections are all ellipses. One particular ellipsoid of revolution, also called the "normal earth" is the one having the same angular velocity and the same mass as the actual earth, the potential $\mathrm{U}_{0}$ on the ellipsoid surface equal to the potential $\mathrm{W}_{0}$ on the geoid, and the centre is coincident with the centre of mass of the earth [1]. Ellipsoid defines mathematical surface approximating the physical reality while simplifying the geometry. Ellipsoid is a good approximation to the shape of the earth but not an exact representation. It is the only regular surface among the three geodetic surfaces; hence it has a regular shape which made it possible to be represented mathematically, and therefore enables computation to be carried on it [2 - 7].

One common problem with height systems is the lack of a uniform reference datum. A reference height datum is a smooth surface which is adopted as a basis for heights in a particular locality. Different hypotheses do exist and many height systems have been defined for different vertical datum throughout the world. Each system has advantages and disadvantages with regard to ease of computation, accuracy requirement, data availability, compatibility with GNSS measurements, needs of the user community and the topographic setting in which the heights are used. In areas that are around the coast, the mean sea level is often adopted as the basis for reckoning heights. However, defining the mean sea level and carrying it to the hinterland have always been problematic resulting in poor or uncoordinated height system, especially in Nigeria. The height referring to the Mean Sea Level is orthometric height. One of the major arguments for the use of orthometric height is its relationship with ocean (water body).

However, direction of flow of fluid is not controlled by height; it is actually the force of gravity that governs fluid flow, not height. 


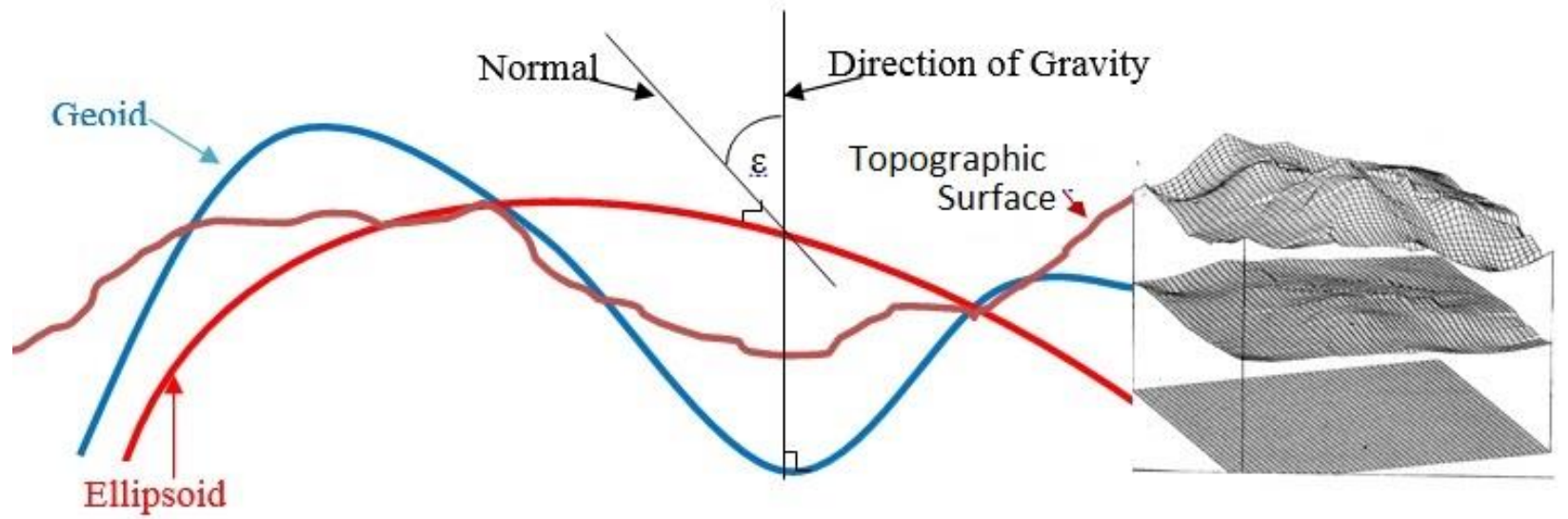

Figure 1: The Three Geodetic Surfaces and their Pictorial Representation

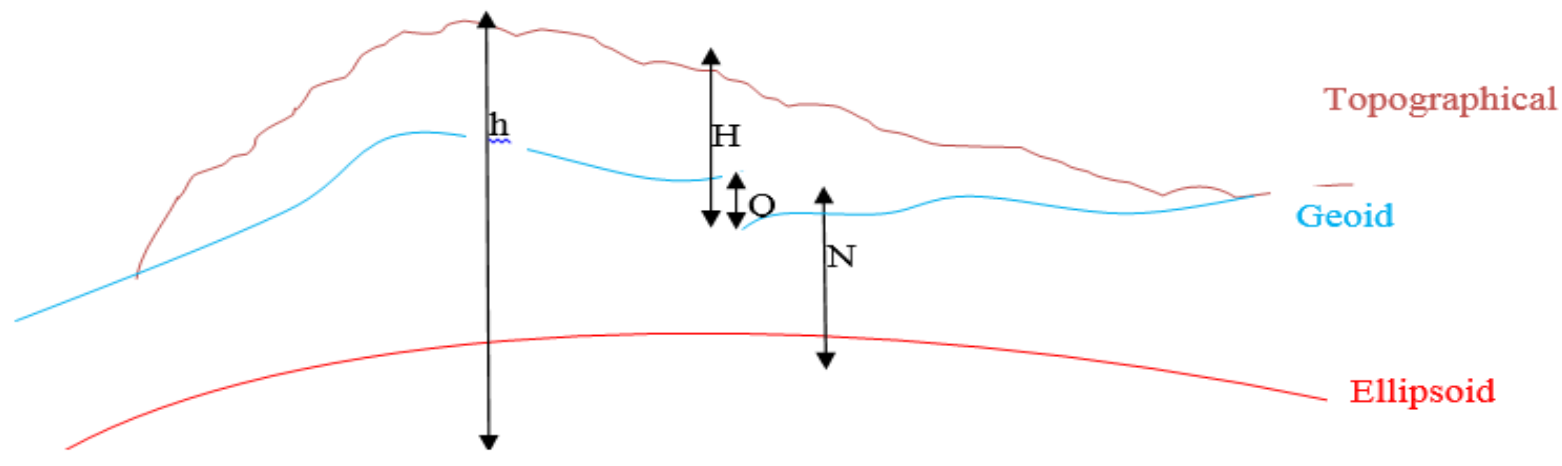

Figure2: The Three Geodetic Surfaces and the offset of vertical datum with respect to the geoid

Therefore, selection of a height system that neglects gravity, or does not use it rigorously, allows the possibility of fluids appearing to flow 'up hills'. Clearly, such a system is counter-intuitive, thus reminding us that only heights properly related to the earth's gravity field are natural and physically meaningful for most (but not all) applications [8].

\subsection{Engineering Surveys}

Engineering surveys are surveying operation required for engineering and construction projects such as route surveying, levelling, setting out of various types, monitoring of structure and so on. Most (if not) all engineering surveys require height measurements. Optical levelling is one of the traditional techniques for measuring height differences especially for engineering surveys. Although the technique does not have a high-tech appearance, it is labour intensive and costly. This technique is still recognized as the most precise and reliable method for height difference measurements. Unfortunately, the conventional nature of the technique makes it less attractive for high-profile research proposals. Research focus has shifted to high-tech satellite techniques such as GPS and In SAR. Since height information can be obtained from these technologies, it is better to use such information in engineering surveys such that resources used for acquiring orthometric height information can be used for other developmental purposes [9].

Spirit levelling is the dominant technique for providing elevation above MSL. The equipment are inexpensive and the method is highly accurate. However, it is labour intensive over long distances and the field procedures are tedious and prone to human, systematic and random errors. In some areas, it is often impossible to perform spirit levelling due to weather and terrain conditions. ([10], [11], [12], [13], [14], [5], [15]).

Ellipsoidal height is fast, easy and convenient to obtain from GPS and is equally useful. To make full use of the three-dimensional potentials of GPS, one needs to determine the separation between the ellipsoid and the geoid. This separation is known as geoidal undulation $(\mathrm{N})$.

\subsection{Relationship Between Ellipsoidal and Orthometric Heights}

The relationship between the ellipsoid and the geoid can be represented mathematically by:

Vol. 35, No. 4, October 2016 


$$
h-H=N
$$

In (1), $\mathrm{h}$ is the ellipsoidal height, $\mathrm{H}$ is the Orthometric height, and $\mathrm{N}$ is the geoidal undulation,

Equation (1) can be stated as:

$$
h-H-N=0
$$

However, Equation (2) may not be valid because of the offset of the vertical datum with respect to the geoid. This offset of the vertical datum with respect to the geoid may be represented by $Q$ and hence equation 2 becomes:

$$
h-H-N=Q
$$

$\mathrm{Q}$ can be represented diagrammatically in Figure 2 .

The offset of the vertical datum with respect to the geoid (Q) is very small and always neglected in engineering surveys.

\section{STUDY AREA}

The study area lies between (Latitude 4045' 18.49512 and 4053' 37.49854) and Longitude 6 $6^{\circ} 54^{\prime} .00249$ and $7^{00} 08^{\prime} 10.1036$. Figure 3 shows the study area, while Figure 4 shows the position of points within the study area. The study area lies within the oil rich Niger Delta with many companies, business organizations and government agencies. Many of these organizations use the services of surveyors for projects that need height information. The surveyors working within the study area usually experience difficulty in getting controls, and in most cases established a local datum to do the work. This practice has created a situation where many different height values which are irreconcilable, exist in the area. The flat nature of the metropolis and the care-free culture of waste disposal on the part of the residents have created serious flooding and other environmental problems. It is therefore a good thing that the government in the state has thought it necessary not only to produce the topographical map of Port Harcourt metropolis, but also to address the problem of harmonizing the height systems.

\section{FIELD OPERATIONS}

The field operations were for the purposes of acquiring the ellipsoidal heights and levelled heights for a number of well distributed points in the project area. Geodetic levelling and GPS field exercises were conducted in this work.

\subsection{Geodetic Levelling}

Geodetic levelling were made at selected routes and locations around the main Business District of Port Harcourt. Guidelines and specifications for control of geodetic surveys in Nigeria were followed strictly to ensure that the levelling operation is consistent with Nigerian geodetic standards. The MSL benchmark established by the Nigerian Ports Authority was adopted as the datum. The routes were levelled in loops of one kilometre span, and the misclosure was made not to exceed $2 \mathrm{~mm}$. The Geodetic levelling was also subjected to Least Squares adjustment. The Least Squares adjustment was carried out by Akom Surveys. Figure 5 shows the establishment of height datum by differential levelling.

\subsection{GNSS Observation}

Differential GNSS observations were made at the most suitable locations along the levelling routes. The derived coordinates were comparable to GNSS standard accuracy. GPS observations were also made to some existing controls, particularly those of the Office established by the Surveyor General of the Federation and Shell Petroleum Development Company (SPDC).

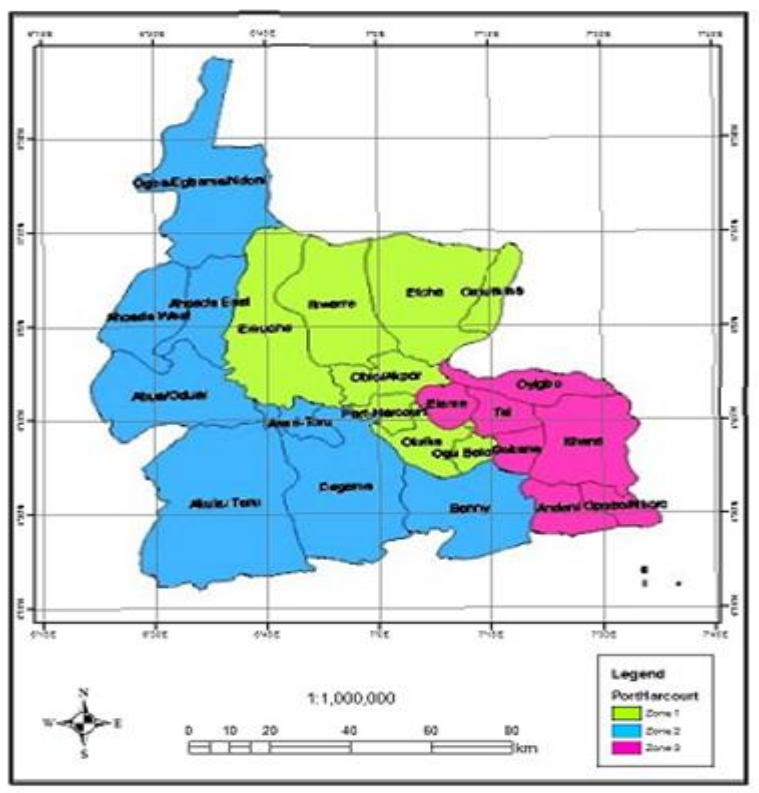

Figure 3: Map of the study Area

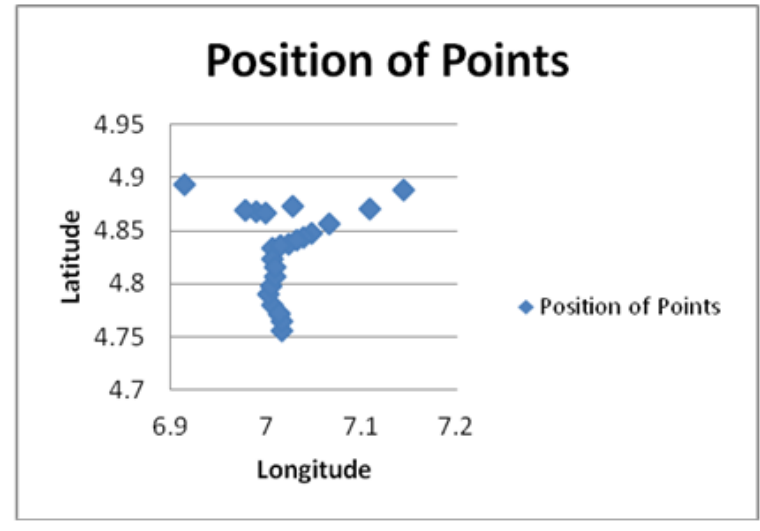

Figure 4: Distribution of points used for the study 


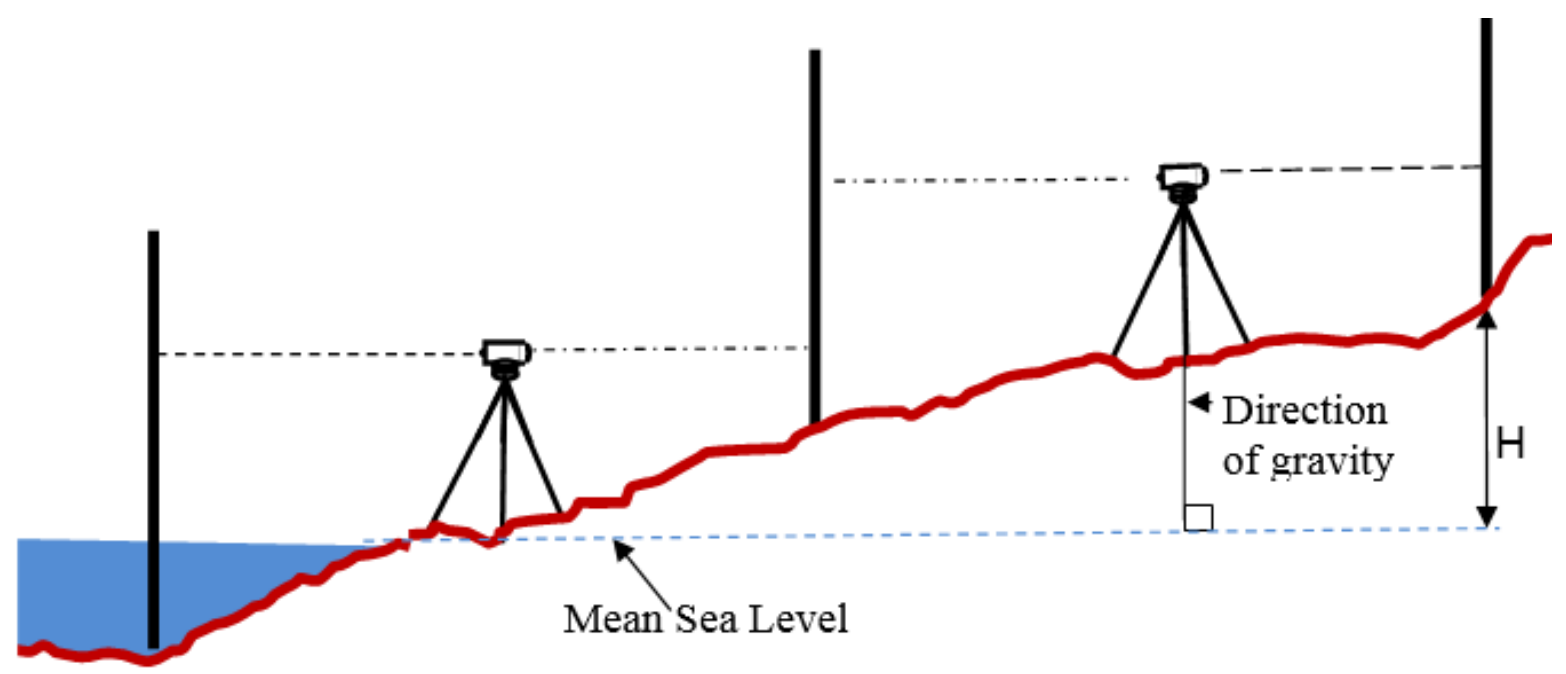

Figure 5: Establishment of Height Datum by Differential Levelling

\section{RESULTS AND DISCUSSION}

Ellipsoidal heights were extracted from the results of the GPS observations. The observations of the geodetic levelling operation carried out were reduced and processed to get the orthometric heights. The results of the data acquisition are shown in Table 1.

From equation 1:

$$
\begin{aligned}
h_{1-} h_{2}-H_{1}+ & H_{2} \\
& =N_{1}-N_{2} \text { or }\left(h_{1}-h_{2}\right)-\left(H_{1}\right. \\
& \left.-H_{2}\right)=N_{1}-N_{2}
\end{aligned}
$$

We observed that from Table 1, the ellipsoidal and orthometric height differences followed the same pattern, despite the differences in the values, which shows that the two results are true representation of the same terrain.

In most engineering surveys, differences in elevation are always required. In fact, it is difference in heights that are measured during levelling operations. The differences in elevation between two successive points for the series of orthometric and ellipsoidal heights were obtained and are shown in Table 2 .

\begin{tabular}{|c|c|c|c|c|c|c|}
\hline $\begin{array}{l}\mathrm{S} / \\
\mathrm{N}\end{array}$ & $\begin{array}{l}\text { Station } \\
\text { Name }\end{array}$ & $\begin{array}{c}\text { Latitude } \\
\text { (Degrees) }\end{array}$ & $\begin{array}{l}\text { Longitude } \\
\text { (Degrees) }\end{array}$ & $\begin{array}{c}\text { Ellipsoidal Height } \\
\mathrm{h}(\mathrm{m})\end{array}$ & $\begin{array}{c}\text { Orthometric Height } \\
\mathrm{H}(\mathrm{m})\end{array}$ & $\begin{array}{c}\text { Undulation } \\
\mathrm{N}(\mathrm{m})\end{array}$ \\
\hline 1 & AP4 & 4.868335803 & 6.989905397 & 35.849 & 16.92611 & 18.92289 \\
\hline 2 & AP1 & 4.869537347 & 6.977927531 & 33.72 & 14.80812 & 18.91188 \\
\hline 3 & $\begin{array}{c}\text { P10 } \\
\text { BALOGUN }\end{array}$ & 4.866625981 & 6.999611117 & 36.084 & 17.18136 & 18.90264 \\
\hline 4 & PW401 JB & 4.856129603 & 7.066638197 & 40.402 & 21.69216 & 18.70984 \\
\hline 5 & RPCS 209p & 4.771628736 & 7.013283025 & 29.885 & 10.59824 & 19.28676 \\
\hline 6 & HS 8 & 4.755137533 & 7.016561928 & 26.028 & 6.986 & 19.042 \\
\hline 7 & RPCS 146p & 4.872683436 & 7.028375606 & 35.644 & 16.22694 & 19.41706 \\
\hline 8 & ZVS 3003 & 4.847971156 & 7.04781145 & 34.957 & 15.98616 & 18.97084 \\
\hline 9 & PT.1 EMMA & 4.764749311 & 7.016644586 & 30.178 & 10.88864 & 19.28936 \\
\hline 10 & PT.2 EMMA & 4.779625886 & 7.006976883 & 30.694 & 11.786 & 18.908 \\
\hline 11 & PT.3 EMMA & 4.790218708 & 7.00227435 & 25.195 & 6.22827 & 18.96673 \\
\hline 12 & PHCS 1s & 4.772389314 & 7.013525022 & 30.796 & 11.798 & 18.998 \\
\hline 13 & PT.4 EMMA & 4.798391819 & 7.005574083 & 30.693 & 11.69056 & 19.00244 \\
\hline 14 & PT.8 EMMA & 4.833761764 & 7.007032608 & 26.789 & 7.8509 & 18.9381 \\
\hline 15 & PT.4 ABDUL & 4.837173481 & 7.022857481 & 32.842 & 13.8392 & 19.0028 \\
\hline 16 & PT.5 EMMA & 4.806938314 & 7.009407025 & 29.374 & 10.3801 & 18.9939 \\
\hline 17 & PT.7 EMMA & 4.823872525 & 7.006017658 & 33.379 & 14.37161 & 19.00739 \\
\hline
\end{tabular}
Statistics from these differences are shown in Table 3.

Table 1: Results of GPS and Geodetic Levelling 


\begin{tabular}{|c|c|c|c|c|c|c|}
\hline $\begin{array}{l}\mathrm{S} / \\
\mathrm{N}\end{array}$ & $\begin{array}{l}\text { Station } \\
\text { Name }\end{array}$ & $\begin{array}{l}\text { Latitude } \\
\text { (Degrees) }\end{array}$ & $\begin{array}{l}\text { Longitude } \\
\text { (Degrees) }\end{array}$ & $\begin{array}{c}\text { Ellipsoidal Height } \\
\mathrm{h}(\mathrm{m})\end{array}$ & $\begin{array}{c}\text { Orthometric Height } \\
\text { H(m) }\end{array}$ & $\begin{array}{l}\text { Undulation } \\
\mathrm{N}(\mathrm{m})\end{array}$ \\
\hline 18 & PT.9 EMMA & 4.836566356 & 7.015292797 & 29.141 & 10.16598 & 18.97502 \\
\hline 19 & PT.6 EMMA & 4.815540608 & 7.009750308 & 34.514 & 15.43661 & 19.07739 \\
\hline 20 & PT.2 ABDUL & 4.844335522 & 7.039518178 & 32.24 & 13.65394 & 18.98606 \\
\hline 21 & PT.3 ABDUL & 4.840752114 & 7.031318094 & 26.75 & 7.76967 & 18.98033 \\
\hline 22 & $\begin{array}{l}\text { UNIPORT } \\
\text { GATE }\end{array}$ & 4.893748844 & 6.914445136 & 29.712 & 10.867 & 18.845 \\
\hline 23 & PP 9 & 4.888250167 & 7.144473222 & 33.57 & 14.46016 & 19.10984 \\
\hline 24 & PP 5 & 4.870257625 & 7.108861117 & 38.802 & 19.75216 & 19.04984 \\
\hline
\end{tabular}

Table 2: Orthometric and Ellipsoidal Height Differences

\begin{tabular}{ccccccc}
\hline S/N & Station Name & Ellipsoidal Height $\mathrm{h}(\mathrm{m})$ & Orthometric Height $\mathrm{H}(\mathrm{m})$ & Dh $(\mathrm{m})$ & DH $(\mathrm{m})$ & Dh-DH $(\mathrm{m})$ \\
\hline 1 & AP4 & 35.849 & 16.92611 & & & \\
2 & AP1 & 33.72 & 14.80812 & 2.129 & 2.11799 & 0.01101 \\
3 & P10 BALOGUN & 36.084 & 17.18136 & -2.364 & -2.37324 & 0.00924 \\
4 & PW401 JB & 40.402 & 21.69216 & -4.318 & -4.5108 & 0.1928 \\
5 & RPCS 209P & 29.885 & 10.59824 & 10.517 & 11.09392 & -0.57692 \\
6 & HS 8 & 26.028 & 6.986 & 3.857 & 3.61224 & 0.24476 \\
7 & RPCS 146P & 35.644 & 16.22694 & -9.616 & -9.24094 & -0.37506 \\
8 & ZVS 3003 & 34.957 & 15.98616 & 0.687 & 0.24078 & 0.44622 \\
9 & PT.1 EMMA & 30.178 & 10.88864 & 4.779 & 5.09752 & -0.31852 \\
10 & PT.2 EMMA & 30.694 & 11.786 & -0.516 & -0.89736 & 0.38136 \\
11 & PT.3 EMMA & 25.195 & 6.22827 & 5.499 & 5.55773 & -0.05873 \\
12 & PHCS 1s & 30.796 & 11.798 & -5.601 & -5.56973 & -0.03127 \\
13 & PT.4 EMMA & 30.693 & 11.69056 & 0.103 & 0.10744 & -0.00444 \\
14 & PT.8 EMMA & 26.789 & 7.8509 & 3.904 & 3.83966 & 0.06434 \\
15 & PT.4 ABDUL & 32.842 & 13.8392 & -6.053 & -5.9883 & -0.0647 \\
16 & PT.5 EMMA & 29.374 & 10.3801 & 3.468 & 3.4591 & 0.0089 \\
17 & PT.7 EMMA & 33.379 & 14.37161 & -4.005 & -3.99151 & -0.01349 \\
18 & PT.9 EMMA & 29.141 & 10.16598 & 4.238 & 4.20563 & 0.03237 \\
19 & PT.6 EMMA & 34.514 & 15.43661 & -5.373 & -5.27063 & -0.10237 \\
20 & PT.2 ABDUL & 32.24 & 13.65394 & 1.874 & 1.78267 & 0.09133 \\
21 & PT.3 ABDUL & 26.75 & 7.76967 & 5.89 & 5.88427 & 0.00573 \\
22 & UNIPORT GATE & 29.712 & 10.867 & -2.962 & -3.09733 & 0.13533 \\
23 & PP 9 & 33.57 & 14.46016 & -3.858 & -3.59316 & -0.26484 \\
24 & PP 5 & 38.802 & 19.75216 & -5.232 & -5.292 & 0.06 \\
\hline
\end{tabular}

Table 3: Statistics from Orthometric and Ellipsoidal Height Differences

\begin{tabular}{ccccccc}
\hline S/N & Station Name & Dh $(\mathrm{m})$ & DH $(\mathrm{m})$ & $\mathrm{X}=\mathrm{Dh}-\mathrm{DH}(\mathrm{m})$ & $(\mathrm{Dh}-\mathrm{DH})(\mathrm{sqm})$ & Square of $(\mathrm{X}-\mathrm{Mean}(\mathrm{X}))(\mathrm{sqm})$ \\
\hline 1 & AP4 & & & & & \\
2 & AP1 & 2.129 & 2.11799 & 0.01101 & 0.00012122 & 0.000265676 \\
3 & P10 BALOGUN & -2.364 & -2.37324 & 0.00924 & $8.53776 \mathrm{E}-05$ & 0.000211109 \\
4 & PW401 JB & -4.318 & -4.5108 & 0.1928 & 0.03717184 & 0.039239482 \\
5 & RPCS 209P & 10.517 & 11.09392 & -0.57692 & 0.332836686 & 0.326761337 \\
6 & HS 8 & 3.857 & 3.61224 & 0.24476 & 0.059907458 & 0.062524792 \\
7 & RPCS 146P & -9.616 & -9.24094 & -0.37506 & 0.140670004 & 0.136730164 \\
8 & ZVS 3003 & 0.687 & 0.24078 & 0.44622 & 0.199112288 & 0.203860901 \\
9 & PT.1 EMMA & 4.779 & 5.09752 & -0.31852 & 0.10145499 & 0.098113296 \\
\hline
\end{tabular}




\begin{tabular}{ccccccc}
\hline S/N & Station Name & Dh $(\mathrm{m})$ & DH $(\mathrm{m})$ & $\mathrm{X}=\mathrm{Dh}-\mathrm{DH}(\mathrm{m})$ & $(\mathrm{Dh}-\mathrm{DH})(\mathrm{sqm})$ & Square of $(\mathrm{X}-\mathrm{Mean}(\mathrm{X}))(\mathrm{sqm})$ \\
\hline 10 & PT.2 EMMA & -0.516 & -0.89736 & 0.38136 & 0.14543545 & 0.149497898 \\
11 & PT.3 EMMA & 5.499 & 5.55773 & -0.05873 & 0.003449213 & 0.002855878 \\
12 & PHCS 1s & -5.601 & -5.56973 & -0.03127 & 0.000977813 & 0.000674982 \\
13 & PT.4 EMMA & 0.103 & 0.10744 & -0.00444 & $1.97136 \mathrm{E}-05$ & $7.21786 \mathrm{E}-07$ \\
14 & PT.8 EMMA & 3.904 & 3.83966 & 0.06434 & 0.004139636 & 0.004848278 \\
15 & PT.4 ABDUL & -6.053 & -5.9883 & -0.0647 & 0.00418609 & 0.003529598 \\
16 & PT.5 EMMA & 3.468 & 3.4591 & 0.0089 & 0.00007921 & 0.000201344 \\
17 & PT.7 EMMA & -4.005 & -3.99151 & -0.01349 & 0.00018198 & $6.72469 \mathrm{E}-05$ \\
18 & PT.9 EMMA & 4.238 & 4.20563 & 0.03237 & 0.001047817 & 0.001418244 \\
19 & PT.6 EMMA & -5.373 & -5.27063 & -0.10237 & 0.010479617 & 0.009424608 \\
20 & PT.2 ABDUL & 1.874 & 1.78267 & 0.09133 & 0.008341169 & 0.009335343 \\
21 & PT.3 ABDUL & 5.89 & 5.88427 & 0.00573 & $3.28329 \mathrm{E}-05$ & 0.000121431 \\
22 & UNIPORT GATE & -2.962 & -3.09733 & 0.13533 & 0.018314209 & 0.019773866 \\
23 & PP 9 & -3.858 & -3.59316 & -0.26484 & 0.070140226 & 0.067366421 \\
24 & PP 5 & -5.232 & -5.292 & 0.06 & 0.0036 & 0.004262729 \\
& Sum & -2.953 & -2.82605 & -0.12695 & 1.141784839 & 1.141085347 \\
& Mean & -0.12304 & -0.11775 & -0.00528958 & 0.047574368 & 0.047545223 \\
\hline
\end{tabular}

\subsection{Root Mean Square Error:}

The Root-Mean-Square error (RMSE) of the ellipsoidal height differences and orthometric height differences was found using Equation (5) given by [16].

$$
R M S E=\sqrt{\left(\frac{1}{n} \sum_{i=1}^{n} e_{i}^{2}\right)}
$$

In (5), $e_{i}$ is the ellipsoidal height differences orthometric height differences; $\mathrm{N}=24$ and RMSE $=$ 0.21812

\subsection{Standard Deviation of Differences in Ellipsoidal Height and Orthometric Height Differences}

The standard deviation for the differences in ellipsoidal and orthometric heights is given by [17] as:

$$
s=\sqrt{\frac{1}{N-1} \sum_{i=1}^{N}\left(x_{i}-\bar{x}\right)^{2}}
$$

Standard deviation $=0.222738$

The elevation differences computed from ellipsoidal height and that of orthometric height for the series of points differed by amount ranging from $-57 \mathrm{~cm}$ to $44 \mathrm{~cm}$ with a mean difference of $5 \mathrm{~mm}$ over a total distance of about $139.114 \mathrm{~km}$. We suspect outlier in two extreme cases, they are more than two standard deviations. If we remove these values $(-57 \mathrm{~cm}$ and $44 \mathrm{~cm}$ ), the ranges and differences are closer. Hence ellipsoidal and orthometric height differences can be substituted for each other. This is in agreement with [18] which stated that 'the elevation differences between points in the same triangular loop for the two methods sum up to zero'. Thus GNSS relative height is favorably compared with relative height of conventional spirit levelling. The result meets the accuracy of $27 \mathrm{~mm} \sqrt{k}$ where $\mathrm{k}$ is in kilometer, which is the requirement for engineering surveys.

\section{SOURCES OF ERROR}

\subsection{Datum Inconsistencies Inherent Among the Height Types}

There are differences between the reference surfaces in each of the height data. Ellipsoidal heights from GPS refer to WGS 84 reference ellipsoid used to determine the satellite orbits. Orthometric heights, computed from levelling refer to a local vertical datum, which is usually defined by fixing one or more tide-gauge stations.

\subsection{Systematic Errors and Distortions in the Height Data}

Systematic errors are mainly caused by poorly modelled GPS errors, such as atmospheric refraction (especially tropospheric errors). Although spiritlevelled height differences are usually quite precise, the derived orthometric heights for a region or nation are supposed to be the result of an over-constrained levelling network adjustment, but, height adjustment in Nigeria are yet to be properly adjusted which might have introduced distortions. 


\subsection{Assumptions and theoretical approximations made in processing observed data}

Common approximations neglect sea surface topography (SST) correction for measured tide gauge values, which results in significant deviation of readings from mean sea level. Isioye (2008) observed that this category of errors is already known to exist at the Lagos tide gauge station in Nigeria. Other factors include the use of approximations for normal or orthometric height corrections and the use of normal gravity values instead of actual surface gravity values in computing orthometric heights [19].

\subsection{Instability of Reference Station Monuments and Deviations of Control Station Coordinates:}

This can be attributed to geodynamic effects such as post-glacial rebound e.g. crustal motion, plate tectonics movement, deformation and land subsidence. Most GPS processing software eliminate all tidal effects when computing the final coordinate differences. It is better to use non-tidal geoid for consistency. More details on error caused by mixing ellipsoidal heights referring to a non-tidal crust and orthometric heights whose reference surface is the mean or zero geoid is given in [20]in [8].

\subsection{OtherSources of Errors from GPS Observation}

Other sources of errors include the effect of earth gravitational potential, non sphericity of centre body, atmospheric drag, solar \& lunar effect, earth and ocean tides, radiation and pressure ([21], [22]).

[23] classified GPS errors into:

i. User's range error which includes ephemeris errors, satellite clock errors,ionospheric delays, tropospheric delays and atmospheric errors.

ii. User equipment errors which are the receiver's errors,multipath errors, jumping and spoofing, mask angle and obstruction.

\subsection{Sources of Errors in Levelling}

Sources of errors in levelling include the effect of refraction and scintillation, temperature, local instability of benchmarks, astronomical effect, gravity, systematic movement of staves and instrument, staff calibration and compensator [24].Approximate normal or orthometric height corrections also leads to errors in levelling [6].

\section{CONCLUSION AND RECOMMENDATIONS}

\subsection{Conclusion}

In this study, levelled heights were established along with GNSS observations in some parts of Port Harcourt metropolis to unify the height system. The height differences between ellipsoidal and orthometric heights were investigated. Mean accuracy of $13.2 \mathrm{ppm}$ was obtained over a total distance of $139.114 \mathrm{~km}$. This result meets the accuracy of $27 m m \sqrt{k}$ where $\mathrm{k}$ is in kilometer, which is the requirement for engineering surveys. GNSS relative height is therefore favorably compared with relative height of conventional spirit levelling. GNSS ellipsoidal height differences can serve any purpose required by surveyors, engineers and other height users. The height differences in GNSS observation $(\Delta \mathrm{h})$ and spirit levelling $(\Delta \mathrm{H})$ are minimal over a flat terrain.

\subsection{Recommendations}

The following recommendations are given based on this work:

(1) GNSS ellipsoidal height differences can serve any purpose required for engineering surveys.

(2) For uniformity of results, it is recommended that GNSS and geodetic leveling observations be carried out at the same time, so that better height differences can be obtained.

(3) The area of coverage for the data used in this study is quite small; this needs to be extended for further investigation.

\section{REFERENCES}

[1] Xiong, Li and Hans-Jürgen, G. "Ellipsoid, geoid, gravity, geodesy, and geophysics", Journal of Geophysics.. Vol. 66. No 6. pp 1660-1668. (2001).

[2] Rapp, R. H. "The earth gravity field to degree and order 180 Using SEASAT Altimeter data, Terestrial gravity data and other data", Reports No. 322. Department of Geodetic Science and Surveying, Ohio State University, Columbus. 1(981).

[3] Vanicek, P. and Krakiwsky, E. J. Geodesy: The Concepts, 2nd corrected Edition, North Holland, Amsterdam. (1986).

[4] Petrovskaya, M. S. and Pishchukhina, K. V.“Geoid heights approximation", I. Kinematika vcnnhg Fiz. Nebesn. Tel, Tom 5, No. 1, p. 26 - 32. 1989.

[5] Vanicek, P. "An Online Tutorial in Geodesy", Academic Press, University of New Brunswick, $2015 . \quad$ http://www2.unb.ca/gge/Resources/ GeodesyTutorial.pdf. Accessed on November 24, (2015).

Vol. 35, No. 4, October 2016 
[6] Moka, E. C. and Agajelu, S. I. "On the Problems of computing orthometric heights from GPS Data", A paper presented at the 1st international workshop on Geodesy \& Geodynamics, Toro, Bauchi State, Nigeria, pp. 85 - 91. 2006.

[7] Jokeli, C. Geometric Reference System in Geodesy, Lecture Notes in Geometric Geodesy and Geodetic Astronomy, Division of Geodesy and Geospatial Science, Ohio State University, Columbus Ohio. 2006.

[8] Isioye, 0. A. "Options for the definition of the Nigerian height datum with a view to its unification in a global vertical datum", A M.Sc. project Department of Surveying and Geoinformatics, University of Lagos. 2008.

[9] Grebenitcharsky, R. "Back to the roots: Joint analysis of historical and contemporary levelling surveys for land subsidence monitoring". 2005.

[10] Bomford, G .Geodesy, Clerendon Press, London. $4^{\text {th }}$ edition 1980.

[11] Fajemirokun, F. A. "The Nigerian geodetic control system",An appraisal. Proceedings of the XVth Annual General Meeting of the Nigerian Institution of Surveyors held in Abeokuta. 22 $2^{\text {nd }}-24^{\text {th }}$ April, 1980.

[12] Fajemirokun, F. A. “On the problems of local origins in Nigeria", The Map Maker, Journal of the Nigerian Institution of Surveyors, Vol. 7, No1, 1981.

[13] Featherstone, W. E, Dentith, M. C. and Kirby, J. F. "Strategies for the accurate determination of orthometric heights from GPS", Survey Review Vol. 34. pp. 267. 1998.

[14] James, M.A. and Minkhail, E. M. Surveying theory and practice, $7^{\text {th }}$ Ed. WCB / McGraw Hill USA. (1998).

[15] Uzodinma N. V. "VLBI, SLR and GPS data in the Nigerian primary triangulation network - what benefit to future research and the national economy", Proceeding of 1st international workshop on geodesy and geodynamics. Centre for Geodesy and Geodynamics, Toro, Nigeria. Feb 5th to $10^{\text {th }} 2005$.

[16] www.nauticalcharts.noaa.gov/csdl/skillassess.html, Accessed in (2012).

[17] Keller, G. and Warrack, B., Statistics for management and economics, Sixth Edition, Thompson Learning Inc., Pacific Grove, USA.. 832pp. 2003.

[18] Aleem, K. F. "GPS and Remote Sensing of environment", The Graduate Surveyors. Journal of NISS Vol. 12, pp. 24 - 27. 1996.

[19] Véronneau, M. "The Canadian Gravimetric Geoid Model of 2000 (CGG2000)", Internal Report, Geodetic Survey Division, Earth Sciences Sector, Natural Resources Canada, Ottawa, Canada. 2002.

[20] Poutanen, M., Vermeer, M., and Mäikinen, J. "The permanent tide in GPS positions", Journal of Geodesy, vol. 70, pp. 499-504. 1996.

[21] King R. W, Master, E. G. Rizo, C. Stolze A. and Collins, J. "Surveying with Global Positioning System $G P S$ ", Dummler Verlag Kalserstra Be, Germany, 1985.

[22] Aleem, K. F. Computation of Global Positioning System carrier phase observables from earth-fixed satellites coordinates, A M.Sc. project submitted to the Department of Geoinformatics and Surveying, University of Nigeria, Enugu Campus.. Unpublished. 2001.

[23] Trimble Navigation Ltd. "GPS", The first Global Navigation Satellite System. California, USA. 2007.

[24] Obong, M. B. A study of analysis of the geodetic levelling in Nigeria, A Doctor of Philosophy thesis of the Department of Surveying, University of Newcastle upon Tyne. 1985. 